\title{
UTERINE CONTRACTIONS IN THE EWE DURING PROGESTAGEN-REGULATED OESTRUS
}

\author{
H. W. HAWK AND S. E. ECHTERNKAMP \\ United States Department of Agriculture, \\ ARS Animal Physiology and Genetics Institute, \\ Agricultural Research Center, Beltsville, Maryland 20705, U.S.A.
}

(Received 9th September 1972)

\begin{abstract}
Summary. Parous ewes were treated orally or intravaginally with synthetic progestagen, or subcutaneously with progesterone. Treatment was begun on Day 8 or 10 of an oestrous cycle and continued for 13 to 17 days. At the oestrus following progestagen withdrawal, the uterus was exposed and uterine contractions observed. Each treatment reduced the number of uterine contractions moving towards the oviducts and increased the number moving towards the cervix. The altered motility pattern probably helps to account for decreased sperm transport to the oviducts at the progestagen-regulated oestrus.
\end{abstract}

Controlling oestrus in ewes by intravaginal or oral administration of synthetic progestagen results in the inhibition of sperm transport to the oviducts at the regulated oestrus (Quinlivan \& Robinson, 1967, 1969; Hawk \& Conley, 1971, 1972).

Sperm transport through the uterus is generally considered to be aided by uterine contractions (Blandau, 1969). This study was made to examine the effect of progestagen treatment on the direction of uterine contractions at the regulated oestrus.

Parous Rambouillet ewes, 6 to 8 years of age, were treated in one of the following ways (Table 1): (1) no treatment; (2) 10 or $20 \mathrm{mg}$ progesterone daily, administered subcutaneously in $1 \mathrm{ml}$ corn oil; (3) $0.3 \mathrm{mg}$ melengestrol acetate (MGA) daily or (4) $60 \mathrm{mg}$ medroxyprogesterone acetate (MAP) daily, administered orally in a soybean-meal mix in a gelatin capsule; (5) an intravaginal sponge, impregnated with $60 \mathrm{mg}$ MAP, inserted into the anterior vagina and left in place until removed. All treatments were begun on Day 8 or 10 of the oestrous cycle (day of oestrus = Day 0 ) and continued until Day 23 to 25 . On the final day of treatment, the progesterone and orally administered progestagens were given at half the usual dosage.

After progestagen treatment was ended, the ewes were checked for oestrus three times daily. All the ewes included in Table 1 were in oestrus on the 2nd, 3 rd or 4th day after the end of treatment. The time from the end of treatment until oestrus averaged 2.9 days, with no significant differences between the treatment groups.

Each ewe coming into heat was allowed to be mated once by a vasectomized 
ram to establish the certainty of standing oestrus, then she was removed from the pen. Within 1 to $2 \mathrm{hr}$, she was anaesthetized with sodium pentobarbital and a mid-ventral incision was made from the anterior edge of the mammary gland forward for about $10 \mathrm{~cm}$. The incision was held open by the use of a retractor, the uterus was grasped gently and after bringing it to the surface, the uterine horns were spread over the surgical drape. The anterior two-thirds of the uterine horns were brought through the incision without stretching the uterus.

The initial contractions of the uterine horns were erratic but within 3 to 5 min, the contractions assumed a pattern and were then observed for $10 \mathrm{~min}$. Individual contractions were recorded as moving towards the oviduct, towards the cervix, or not moving clearly in either direction. The contractions recorded as moving were localized constrictions which clearly moved lengthwise along the uterine horn in one direction or the other. The contractions recorded as not moving clearly in either direction included powerful contractions which uncoiled and straightened the entire horn, contractions which covered a length

Table 1. Uterine contractions during progestagen-regulated oestrus in the ewe

\begin{tabular}{c|l|c|c|c|c}
\hline & & \multicolumn{4}{|c}{ No. of contractions per 10 min } \\
\cline { 3 - 6 } $\begin{array}{c}\text { Group } \\
\text { no. }\end{array}$ & Treatment & $\begin{array}{c}\text { Moving } \\
\text { towards } \\
\text { oviducts }\end{array}$ & $\begin{array}{c}\text { Moving } \\
\text { neither or } \\
\text { both ways }\end{array}$ & $\begin{array}{c}\text { Moving } \\
\text { towards } \\
\text { cervix }\end{array}$ & Total \\
\hline 1 & Controls (20) & $34 \pm 3$ & $21 \pm 4$ & $8 \pm 2$ & $63 \pm 4$ \\
2 & Progesterone (13) & $15 \pm 4$ & $20 \pm 4$ & $23 \pm 4$ & $58 \pm 6$ \\
3 & MGA oral (18) & $10 \pm 2$ & $21 \pm 2$ & $20 \pm 3$ & $51 \pm 5$ \\
4 & MAP oral (11) & $10 \pm 2$ & $22 \pm 3$ & $17 \pm 3$ & $49 \pm 4$ \\
5 & MAP sponge (11) & $11 \pm 4$ & $20 \pm 3$ & $17 \pm 4$ & $48 \pm 7$ \\
\hline
\end{tabular}

Results are expressed as means \pm S.E. Figures in parentheses are numbers of ewes.

of several centimetres of the horn, localized constrictions which did not move along the horn, and, in a few ewes, blanching of 1 to $3 \mathrm{~cm}$ of the horn, which indicated a weak contraction in the myometrium.

All ewes were still in oestrus at the time the contractions were observed and none had ovulated.

In control ewes, the total number of contractions averaged $6 \cdot 3 / \mathrm{min}$ (Table 1). The proportions of total contractions moving towards the oviducts, not moving clearly in either direction, or moving towards the cervix were $54 \%$, $33 \%$ and $13 \%$, respectively. These figures are similar to those taken previously from cine-film recordings of uterine contractions in other control ewes (6.9 contractions/min and directional movements of $58 \%, 26 \%$ and $16 \%$, respectively; Brinsfield \& Hawk, 1969).

Each progestagen treatment reduced the number of contractions moving towards the oviducts $(P<0.01$ for each treatment group versus the controls). Each progestagen treatment also increased the number of contractions moving towards the cervix (for Group 2 or 3 versus the controls, $P<0.01$; for Group 4 or 5 versus the controls, $P \leqslant 0.05)$. The treatments with synthetic progestagen 
tended to reduce the total number of contractions (Group 3, 4 or 5 versus the controls, $P<0 \cdot 05$ ).

For the fifty-three treated ewes (Groups 2 to 5), the proportions of contractions moving towards the oviduct, not moving clearly in either direction, or moving towards the cervix were $22 \%, 40 \%$ and $38 \%$, respectively.

In ewes of all groups, the majority of contractions which moved towards the oviducts originated in the posterior portion of the uterine horns and moved anteriorly; most of those moving towards the cervix originated near the uterotubal junction and moved posteriorly. The contractions that did not move clearly in either direction generally originated near the centre of the horn or covered much of the entire length of the horn.

The effect of the progestagen treatments in reducing the number of contractions moving towards the oviducts and increasing the number moving towards the cervix may account at least in part for the previously reported decrease in sperm transport to the oviducts in oestrous ewes following progestagen treatment (Quinlivan \& Robinson, 1967, 1969; Hawk \& Conley, 1971, 1972).

The effect of progestagen on the direction of uterine contractions in the ewe is somewhat similar to the effect of placing a plastic spiral in the uterine lumen, which 'reverses' the direction of uterine contractions and inhibits sperm transport (Hawk, 1967; Brinsfield \& Hawk, 1969). Whether the effects of a plastic spiral and progestagen treatment have similar physiological bases is not clear, but it appears that uterine motility patterns in oestrous ewes can be disrupted by seemingly diverse treatments.

The authors express appreciation to Dr R. G. Zimbelman, The Upjohn Company, Kalamazoo, Michigan, for supplying the progestagens. This study was supported in part by the National Institute of Child Health and Human Development, National Institutes of Health, Bethesda, Maryland.

\section{REFERENCES}

BlANDAu, R. J. (1969) Gamete transport-comparative aspects. In: The Mammalian Oviduct, p. 129. Eds. E. S. E. Hafez and R. J. Blandau. The University of Chicago Press, Chicago.

Brinsfield, T. H. \& HAwK, H. W. (1969) Modification of the direction of uterine contractions by intra-uterine devices in the ewe. 7. Reprod. Fert. 18, 535.

HAwk, H. W. (1967) Investigations on the anti-fertility effect of intra-uterine devices in the ewe. $\mathcal{F}$. Reprod. Fert. 14, 49.

HAWK, H. W. \& ConLEY, H. H. (1971) Loss of spermatozoa from the reproductive tract of the ewe and intensification of sperm 'breakage' by progestagen. F. Reprod. Fert. 27, 339.

HAWK, H. W. \& ConLEY, H. H. (1972) Investigation of sperm transport failures in ewes administered synthetic progestagen. F. Anim. Sci. 34, 609.

Quinlivan, T. D. \& Robinson, T. J. (1967) The number of spermatozoa in the Fallopian tubes of ewes at intervals after artificial insemination following withdrawal of SC-9880 impregnated intravaginal sponges. In: The Control of the Ovarian Cycle in the Sheep, p. 117. Ed. T. J. Robinson. Sydney University Press, Sydney.

Quinlivan, T. D. \& Robrnson, T. J. (1969) Numbers of spermatozoa in the genital tract after artificial insemination of progestagen-treated ewes. F. Reprod. Fert. 19, 73. 